\title{
Desempenho e características de carcaça de suínos submetidos a diferentes programas de restrição alimentar na fase dos 30 aos $118 \mathrm{~kg}^{1}$
}

\author{
Marcus Vinícius Briganó ${ }^{2}$, Graziela Drociunas Pacheco², Ana Maria Bridi ${ }^{3}$ Alexandre Oba ${ }^{3}$, \\ Nilva Aparecida Nicolao Fonseca ${ }^{3}$, Caio Abércio da Silva ${ }^{3}$
}

1 Trabalho financiado pelo CNPq.

2 Programa de Pós-Graduação em Ciência Animal da Universidade Estadual de Londrina, Caixa Postal 6001, CEP: 86051-970, Londrina - PR.

${ }^{3}$ Departamento de Zootecnia da Universidade Estadual de Londrina, Caixa Postal 6001, CEP: 86051-970, Londrina - PR.

RESUMO - Objetivou-se avaliar o desempenho, as características de carcaça e o peso de órgãos do sistema digestório de suínos submetidos a restrição alimentar. Foram utilizados 40 suínos machos castrados, Landrace $\times$ Large White, distribuídos em delineamento de blocos casualisados, com quatro tratamentos, cinco repetições e dois animais por parcela experimental. Como tratamentos, avaliaram-se quatro programas de restrição alimentar: um controle, com alimentação à vontade durante os 86 dias de experimento; e outros três, com restrição de $20 \%$ no consumo de ração em relação ao grupo controle, durante 21 dias, a partir dos 30, 50 ou $70 \mathrm{~kg}$ de peso corporal (PC). Foram mensurados o consumo diário de ração, o ganho diário de peso e a conversão alimentar. As características de carcaça analisadas foram: peso de carcaça quente e fria, comprimento e rendimento de carcaça, espessura de toucinho, profundidade do músculo Longissimus dorsi, rendimento de carne na carcaça, quantidade de carne na carcaça, área de olho-de-lombo e pesos de fígado, estômago e intestinos delgado e grosso. Os custos de cada programa de alimentação foram avaliados para determinação de sua viabilidade. A conversão alimentar, considerando o período total do experimento, foi melhor nos animais mantidos sob restrição a partir dos $70 \mathrm{~kg}$. Os resultados das avaliações de carcaça e dos pesos dos órgãos não diferiram entre os programas de restrição. As análises de custo apontaram melhor relação para a restrição a partir dos $70 \mathrm{~kg}$ PC. Em todos os programas de alimentação, a restrição alimentar seguida de alimentação à vontade promoveu ganho compensatório.

Palavras-chave: consumo de ração, desempenho, eficiência alimentar, ganho de peso

\section{Performance and carcass traits of pigs submitted to different programs of feed restriction from 30 to $118 \mathrm{~kg}$}

\begin{abstract}
The aim of this work was evaluate the animal performance, the carcass characteristics and the weight of the organs of digestive system of pigs submitted to different periods of feed restriction. A total of 40 barrows, Landrace $\times$ Large White were distributed to randomized block design, to four feed restriction programs, five replications and two animal per experimental unit. Four restrict programs were evaluated: one control, with ad libitum feeding during the 86 days of experiment, and others three, with restriction of $20 \%$ in the feed intake in relation to control group, during 21 days, at 30, 50 or $70 \mathrm{~kg}$ BW. Performance characteristics as daily feed intake, daily weight gain and the feed conversion of the animals were evaluated. Carcass characteristics, as hot and cold carcass weights, length and carcass dressing, subcutaneous fat thickness, Longissimus dorsi muscle depth, lean meat yield, lean meat amount and loin eye area were evaluated. Also were evaluated organs weights, as liver, stomach, small and large intestine. The costs of each program were evaluated to observe their viability. Feed conversion, considering total experimental period, was better for the animals kept on feed restriction from $70 \mathrm{~kg}$ BW. The carcass characteristics evaluations and organs weights did not differ among feed restriction programs. The costs analysis showed a better relation for feed restriction from $70 \mathrm{~kg}$ BW. In all feeding programs, the feed restriction followed by ad libitum feeding promoted a compensatory gain effect for all treatments.
\end{abstract}

Key Words: alimentary efficiency, feed intake, performance, weight gain

\section{Introdução}

O crescimento da atividade suinícola no mundo, segundo Roppa (2005), tem servido de estímulo para investimentos em novas tecnologias pelos produtores e pelas indústrias do setor. Neste sentido, aspectos relacionados à redução dos custos e melhora das características de desempenho e carcaça são constantes e identificam-se com as expectativas dos consumidores. 
A alimentação tem elevada participação na composição dos custos de produção, determinando que muitos recursos técnicos relacionados ao manejo alimentar e ao uso de produtos alternativos nas rações sejam investigados.

A técnica de restrição alimentar, seguida pelo ganho compensatório, é uma metodologia que pode atender esta proposta. Embora não seja um manejo inovador, a restrição e o ganho de peso subseqüente ainda devem ser melhor estudados, em virtude dos diversos fatores relacionados ao processo. Os principais itens que influenciam o ganho compensatório são: o grau de desenvolvimento corporal do animal no início da restrição, a severidade e duração do estresse nutricional e a natureza da restrição (Alves, 2003).

O ganho compensatório é decorrente do aumento do turnover protéico muscular após um período de privação de alimento (Kristensen et al., 2002) e tem, comprovadamente, substanciais efeitos no aumento da porcentagem de carne magra na carcaça, fato que sinaliza a relevância do tema.

Considerando a dinâmica da suinocultura e das inúmeras possibilidades de se praticar um manejo de restrição, realizou-se este trabalho para verificar a utilização de três programas de restrição e avaliar os possíveis efeitos do ganho compensatório sobre o desempenho, as características de carcaça e o desenvolvimento dos órgãos do sistema digestório, além da viabilidade econômica.

\section{Material e Métodos}

O experimento foi realizado no Setor de Suinocultura da Fazenda Escola da Universidade Estadual de Londrina utilizando-se 40 suínos machos castrados, mestiços Landrace $\times$ Large White, com 67 dias de idade e peso corporal (PC) inicial de 30,60 $\pm 5,95 \mathrm{~kg}$. Os animais foram alojados em baias de alvenaria com piso compacto, com $3 \mathrm{~m}^{2}$, equipadas com um bebedouro tipo chupeta para livre acesso à água.

Adotou-se o delineamento de blocos casualizados, distribuídos com base no peso inicial do animal, com quatro tratamentos (períodos de restrição alimentar), cinco repetições e dois animais por parcela experimental (baia). Como tratamentos foram avaliados quatro programas de restrição alimentar: um controle, com alimentação à vontade durante os 86 dias de experimento; e outros três, com restrição de $20 \%$ no consumo de ração em relação ao grupo controle, durante 21 dias, a partir dos 30, 50 ou 70 kg PC. Após o período de restrição, os animais voltaram a receber ração à vontade. Os animais mantidos sob restrição a partir dos 70 kg PC receberam alimentação à vontade durante 30 dias após os 21 dias de restrição.
No fornecimento de ração, foram contabilizados as sobras e os desperdícios. O consumo de ração do dia anterior dos animais alimentados à vontade durante os 86 dias do experimento, em todos os blocos, foi utilizado como referência para aplicação da restrição alimentar aos demais animais em cada período experimental.

Aos animais submetidos à restrição, o fornecimento de ração foi realizado duas vezes ao dia, às 8 e às $17 \mathrm{~h}$. Nas baias dos animais sob restrição, foi instalado um comedouro extra para diminuir os efeitos do comportamento de dominância dos animais.

Durante o período de realimentação, foram registrados semanalmente os pesos e o consumo de ração para avaliação do ganho diário de peso, do consumo diário de ração e da conversão alimentar e observação de possíveis ganhos compensatórios. As rações experimentais foram formuladas segundo exigências mínimas estabelecidas pelo NRC (1998) para as faixas de 20 a $50 \mathrm{~kg}$ PC (fase de crescimento 1), 50 e $80 \mathrm{~kg}$ PC (fase de crescimento 2) e 80 e $120 \mathrm{~kg}$ PC (fase de terminação) (Tabela 1).

Aos 160 dias de idade, os animais foram sacrificados pesando $117 \pm 6,76 \mathrm{~kg}$. O abate foi realizado com insensibilização elétrica, segundo a rotina normal do abatedouro. As carcaças foram mensuradas para determinação dos pesos de carcaça quente e de carcaça resfriada, do rendimento de carcaça e da área de olho-de-lombo, do comprimento de carcaça, da espessura de toucinho e da profundidade do músculo Longissimus dorsi (ABCS, 1973). Utilizando-se esses dados, calcularam-se a porcentagem de carne na carcaça e a quantidade de carne na carcaça, segundo Irgang (2004), por meio das equações:

$$
\operatorname{RCC}(\%)=60-(\mathrm{ET} \times 0,58)+(\mathrm{PM} \times 0,10)
$$

em que: RCC $=$ rendimento de carne na carcaça; $\mathrm{ET}=$ espessura de toucinho; $\mathrm{PM}=$ profundidade do músculo Longissimus dorsi; QCC = PCF $\times$ RCC, em que QCC = quantidade de carne na carcaça; $\mathrm{PCF}=$ peso da carcaça resfriada; RCC = rendimento de carne na carcaça.

Durante o abate, na fase de evisceração, foram separados fígado, estômago e intestinos delgado e grosso. O estômago e os intestinos livres do omento e da gordura adjacente foram esvaziados e pesados.

Os cálculos do índice de eficiência econômica (IEE) e do índice de custo médio (IC) dos programas de restrição foram realizados segundo Barbosa et al. (1992) utilizando-se as equações:

$$
\mathrm{IEE}=\frac{\text { MCe }}{\text { CTei }} \times 100
$$




$$
\mathrm{IC}=\frac{\text { CTei }}{\mathrm{MCe}} \times 100
$$

em que $\mathrm{MCe}=$ menor custo médio observado, baseado na relação entre a quantidade de ração consumida e o quilograma de PC ganho nos programas de restrição; CTei = custo médio do programa de restrição i considerado.

No cálculo dos custos, foram considerados os valores dos ingredientes da ração no mês de fevereiro de 2006: milho grão, R\$ 0,19/kg; farelo de soja, R\$ 0,78/kg; fosfato bicálcico, R\$1,32/kg; calcário, R\$ 0,13/kg; L-lisina, R\$ 7,06/kg; óleo vegetal, R\$ 2,18/kg; suplemento vitamínico, R\$ 3,04/kg; suplemento mineral, $\mathrm{R} \$ 2,68 / \mathrm{kg}$; e sal, $\mathrm{R} \$ 0,38 / \mathrm{kg}$.

Os resultados obtidos no teste de desempenho e os dados de carcaça foram submetidos à análise de variância e as médias, comparadas pelo teste de Tukey, utilizando-se o programa SAEG (UFV, 1997).

Nos testes de desempenho, as análises foram realizadas considerando quatro períodos experimentais, além do período total do experimento. Os períodos foram delimitados considerando a média de peso de todos os animais no

Tabela 1 - Composição percentual, química e energética das

\begin{tabular}{|c|c|c|c|}
\hline Ingrediente & Crescimento 1 & Crescimento 2 & Terminação \\
\hline Milho & 69,564 & 76,608 & 83,173 \\
\hline Farelo de soja & 26,347 & 19,460 & 13,287 \\
\hline Fosfato bicálcico & 1,017 & 0,860 & 0,688 \\
\hline Calcário & 0,604 & 0,504 & 0,538 \\
\hline L-lisina-HCl & 0,025 & 0,064 & 0,014 \\
\hline Óleo vegetal & 1,643 & 1,704 & 1,500 \\
\hline Supl. vit. ${ }^{1,2}$ & 0,500 & 0,500 & 0,500 \\
\hline Supl. $\min .^{3}$ & 0,050 & 0,050 & 0,050 \\
\hline Sal & 0,250 & 0,250 & 0,250 \\
\hline \multicolumn{4}{|l|}{ Valores calculados 4} \\
\hline Proteína bruta (\%) & 18,000 & 15,500 & 13,200 \\
\hline EM (kcal/kg) & 3.265 & 3.265 & 3.310 \\
\hline Matéria seca & 87,959 & 87,838 & 87,700 \\
\hline Fibra bruta (\%) & 3,069 & 2,759 & 2,486 \\
\hline Metionina (\%) & 0,290 & 0,257 & 0,228 \\
\hline Lisina (\%) & 0,950 & 0,800 & 0,600 \\
\hline Cálcio (\%) & 0,600 & 0,500 & 0,450 \\
\hline Fósforo total (\%) & 0,500 & 0,450 & 0,400 \\
\hline
\end{tabular}
rações experimentais

${ }^{1}$ Composição do suplemento vitamínico para as fases de crescimento por kg de produto: vit. A - 1.000.000 UI; vit. D3 - 250.000 UI; vit. E - 2,750 UI; vit. K3 - 625 mg; vit. B1 - 300 mg; vit. B2 - 1.050 mg; vit. B6 - 275 mg; vit. B12 - 3,750 mcg; ácido fólico - $150 \mathrm{mg}$; ácido pantotênico - 3.500 mg; niacina - $5.750 \mathrm{mg}$; colina - $25.000 \mathrm{mg}$; Se - $75 \mathrm{mg}$; promotor de crescimento (sulfato de colistina) - 7,5 g; antioxidante - 2,5 g.

2 Suplemento vitamínico para a fase de terminação por kg de produto: vit. A - 550.000 UI; vit. D3 - 150.000 UI; vit. E - 2.500 UI; vit. K3 - 550 mg; vit. B1 - $175 \mathrm{mg}$; vit. B2 - $900 \mathrm{mg}$; vit. B6 - $275 \mathrm{mg}$; vit. B12 - $3.000 \mathrm{mcg}$; ácido fólico - $150 \mathrm{mg}$; ácido pantotênico - 3.000 mg; niacina - $4.750 \mathrm{mg}$; Se - $75 \mathrm{mg}$; promotor de crescimento (sulfato de colistina) - 6,25 g; antioxidante $-2,5 \mathrm{~g}$.

3 Suplemento mineral por kg de produto: $\mathrm{Fe}-90.000 \mathrm{mg}$; Cu - $16.000 \mathrm{mg}$; Mg - 30.000 mg; Zn - 140.000 mg; Co - 200 mg; I - 850 mg; Se - 120 mg.

4 Valores calculados conforme tabela da EMBRAPA (1991). início do período de restrição até o peso 21 dias após o início da restrição. Assim, o primeiro período correspondeu ao intervalo de peso 30 a $50 \mathrm{~kg}$ PC; o segundo ao peso de 50 a $70 \mathrm{~kg}$ PC; o terceiro de 70 a aproximadamente $90 \mathrm{~kg}$ PC; $\mathrm{e}$ o quarto período dos $90 \mathrm{~kg}$ PC até o abate. Também foram analisados os dados de desempenho de todo o período experimental, ou seja, dos $30 \mathrm{~kg}$ PC até o abate.

\section{Resultados e Discussão}

Os animais submetidos à restrição alimentar aos $30 \mathrm{~kg}$ apresentaram menor consumo de ração, que diferiu $(\mathrm{P}<0,05)$ somente do obtido com restrição aos 50 kg PC(Tabela 2). O consumo de ração dos animais submetidos à restrição aos 30 kg PC diferiu $(\mathrm{P}<0,05)$ do observado com restrição a partir dos $50 \mathrm{~kg}$, mas não foi estatisticamente diferente do obtidos com alimentação à vontade e com restrição aos 70 kg.

O menor ganho de peso do grupo de animais com restrição alimentar aos $30 \mathrm{~kg} P C$ foi proporcional $(\mathrm{P}<0,05)$ ao nível de restrição praticado. A conversão alimentar, por sua vez, não diferiu entre os níveis de restrição aplicados. Os suínos submetidos à restrição durante 21 dias a partir dos 50 kg PC apresentaram o menor consumo de ração $(\mathrm{P}<0,05)$ (Tabela 2). Os animais submetidos à restrição aos $30 \mathrm{~kg}$ PC, em razão do consumo compensatório, apresentaram ingestão $24,5 \%$ maior que a observada naqueles alimentados à vontade, sem restrição. A conversão alimentar desses animais, no entanto, não diferiu da observada nos animais sem restrição, mas apresentou piorou 15,9\%.

A restrição aos $30 \mathrm{~kg}$ PC resultou em maior consumo diário de ração e em ganho diário de peso estatisticamente similar $(\mathrm{P}<0,05)$ ao do grupo sem restrição. Entre os animais submetidos à restrição a partir dos $70 \mathrm{~kg}$ - o consumo de ração desses animais não diferiu do obtido sem restrição -, não houve nenhuma observação que pudesse justificar o ganho de peso inferior ao verificado sem restrição e com restrição aos $30 \mathrm{~kg}$. Nos animais submetidos à restrição aos 50 kg PC, o ganho de peso foi proporcional à restrição alimentar aplicada, em torno de $22 \%$ menor que o observado sem restrição. A conversão alimentar dos animais submetidos à restrição a partir dos $70 \mathrm{~kg}$ foi equivalente $(\mathrm{P}<0,05)$ à do grupo alimentado à vontade. A conversão alimentar foi comprometida no grupo com restrição aos30 kg PC, logo, o aumento no consumo de ração (24\% maior em relação ao controle) influenciou o ganho de peso, mas não otimizou a conversão alimentar. As características nutricionais estabelecidas no trabalho e o padrão genético dos animais avaliados podem ter sido responsáveis por esse resultado, que não correspondeu à melhora da conversão. 
Esse resultado contraria os dados obtidos por Daza et al. (2003), que verificaram os efeitos da restrição de $25 \%$ em relação ao consumo à vontade durante 35 dias, com início aos 32,8 kg PC, e notaram melhora de 9\% na conversão alimentar aos 35 dias após a restrição.

$\mathrm{O}$ consumo pelos animais submetidos à restrição alimentar aos $70 \mathrm{~kg}$ PC foi o menor $(\mathrm{P}<0,05)$ (Tabela 2). A restrição aos $50 \mathrm{~kg}$ PC resultou em consumo compensatório estatisticamente diferente do obtido sem restrição. O grupo submetido à restrição aos 50 kg PC apresentou ganho de peso numericamente superior aos dos demais grupos, porém, sem diferença estatística ( $\mathrm{P}>0,05)$, o que comprova o efeito do consumo sobre o ganho de peso, evidenciado na fase de crescimento dos animais.

As conversões alimentares dos grupos submetidos à restrição alimentar aos 30 e $50 \mathrm{~kg}$ PC diferiram $(\mathrm{P}<0,05)$ da observada no grupo submetido à restrição a partir dos 70 kg PC, porém, não diferiram da obtida no grupo sem restrição alimentar. Nos animais submetidos a restrição, a eficiência alimentar foi menor, indicando que os ganhos subseqüentes ao manejo não foram suficientes para melhorar essa característica (Tabela 3).

Ao início do quarto período experimental, os animais estavam com $90 \mathrm{~kg}$ PC e foram abatidos com $117,32 \pm 6,76 \mathrm{~kg}$ de peso médio. Nesse período não foram verificados resultados no consumo compensatório de ração e no ganho de peso no grupo submetido à restrição aos $70 \mathrm{~kg}$ PC. O fato de não terem sido observadas diferenças no ganho diário de peso no período anterior ( 70 a $90 \mathrm{~kg}$ ) pode ter influenciado a ausência de efeito da restrição sobre o consumo de ração e o ganho diário de peso após os 90 kg (Tabela 3) .

Não foi verificada influência da restrição alimentar $(\mathrm{P}>0,05)$ no consumo e no ganho de peso. A conversão alimentar diferiu somente entre os grupos submetidos à restrição aos 30 e aos 70 kg PC. De acordo com Whittemore (1993), em animais mais jovens, a restrição pode comprometer mais o desempenho, possivelmente por ser uma fase de alta demanda de nutrientes para a formação de tecido muscular. Dessa forma, a restrição alimentar neste período significa efeitos negativos no desempenho dos animais.

As características de carcaça não foram influenciadas ( $\mathrm{P}>0,05)$ pelos níveis de restrição alimentar (Tabela 4). Esses resultados contrariam os descritos por Mersmann et al. (1987), que, aplicando restrições alimentares mais severas, observaram maiores valores de espessura de toucinho e maior porcentagem de gordura nas carnes de pernil e paleta de suínos que desenvolveram ganho compensatório subseqüente à restrição alimentar.

Contudo, os resultados encontrados neste estudo corroboram os reportados por Barbosa et al. (2002a,b), que aplicaram níveis de 5 a 15\% de restrição com 2.083 e 2.252 kcal de energia líquida (EL) na dieta e também não

Tabela 2 - Desempenho de suínos submetidos a quatro programas de restrição alimentar

\begin{tabular}{|c|c|c|c|c|c|}
\hline & \multicolumn{4}{|c|}{ Programa de restrição } & CV (\%) \\
\hline Consumo diário de ração (kg) & 2,101ab & $1,679 b$ & $2,128 \mathrm{a}$ & 1,970ab & 11,984 \\
\hline Ganho de peso diário (kg) & $0,926 a$ & $0,750 \mathrm{~b}$ & $0,976 a$ & 0,938 a & 5,475 \\
\hline Consumo diário de ração (kg) & $3,183 b$ & $3,965 a$ & $2,544 \mathrm{c}$ & $3,123 b$ & 4,185 \\
\hline Ganho de peso diário (kg) & $1,074 a$ & $1,158 \mathrm{a}$ & $0,836 b$ & $0,922 b$ & 6,367 \\
\hline Conversão alimentar & $2,966 c$ & $3,438 a$ & 3,048bc & 3,396ab & 5,929 \\
\hline \multicolumn{6}{|l|}{70 aos $90 \mathrm{~kg}$} \\
\hline Consumo diário de ração (kg) & 3,851 & 3,652 & 3,677 & 4,066 & 6,847 \\
\hline Ganho de peso diário (kg) & 1,194 & 1,154 & 1,100 & 1,234 & 8,307 \\
\hline Conversão alimentar & 3,232 & 3,166 & 3,370 & 3,286 & 5,304 \\
\hline
\end{tabular}

*20\% de restrição alimentar em relação ao grupo controle, durante 21 dias. Letras diferentes indicam diferenças estatísticas pelo teste Tukey (5\%). $\mathrm{CV}$ : coeficiente de variação; PC: peso corporal. 
Tabela 3 - Desempenho de suínos dos $30 \mathrm{~kg}$ até a idade de abate (160 dias) submetidos a quatro programas de restrição alimentar

\begin{tabular}{|c|c|c|c|c|c|}
\hline \multirow[t]{2}{*}{ Parâmetro } & \multicolumn{4}{|c|}{ Programa de restrição } & \multirow[b]{2}{*}{ CV $(\%)$} \\
\hline & $\begin{array}{l}\text { Sem restrição } \\
\text { alimentar }\end{array}$ & $\begin{array}{c}\text { Restrição aos } \\
30 \text { kg PC* }\end{array}$ & $\begin{array}{c}\text { Restrição aos } \\
50 \text { kg PC* }\end{array}$ & $\begin{array}{c}\text { Restrição aos } 70 \\
\text { kg PC* }\end{array}$ & \\
\hline Consumo diário de ração (kg) & 3,135 & 3,197 & 3,060 & 2,998 & 5,628 \\
\hline Ganho de peso diário (kg) & 1,050 & 0,990 & 1,016 & 1,026 & 6,062 \\
\hline Conversão alimentar & $2,992 \mathrm{ab}$ & $3,246 a$ & $3,030 \mathrm{ab}$ & $2,926 b$ & 4,861 \\
\hline
\end{tabular}

*20\% de restrição alimentar em relação ao grupo controle, durante 21 dias.

Letras diferentes indicam diferenças estatísticas pelo teste Tukey (5\%).

$\mathrm{CV}$ : coeficiente de variação; PC: peso corporal.

Tabela 4 - Características de carcaça de suínos submetidos a restrição alimentar nas fases de crescimento e terminação

\begin{tabular}{|c|c|c|c|c|c|}
\hline Característica & \multicolumn{4}{|c|}{ Programa de restrição } & CV $(\%)$ \\
\hline Peso de carcaça quente (kg) & 90,950 & 87,100 & 89,240 & 89,290 & 4,697 \\
\hline Peso de carcaça fria (kg) & 89,030 & 84,360 & 87,420 & 87,420 & 4,809 \\
\hline Comprimento de carcaça $(\mathrm{cm})$ & 101,150 & 97,900 & 98,050 & 99,600 & 2,846 \\
\hline Profundidade de músculo (mm) & 56,166 & 55,756 & 57,458 & 55,992 & 6,971 \\
\hline Rendimento de carcaça quente (\%) & 48,908 & 49,910 & 49,590 & 49,214 & 6,702 \\
\hline Quantidade de carne na carcaça (kg) & 43,590 & 42,128 & 43,166 & 43,142 & 7,887 \\
\hline Área de olho-de-lombo $\left(\mathrm{cm}^{2}\right)$ & 36,788 & 35,710 & 36,868 & 37,160 & 13,236 \\
\hline
\end{tabular}

*20\% de restrição alimentar em relação ao grupo controle, durante 21 dias.

Letras diferentes indicam diferenças estatísticas pelo teste Tukey (5\%).

CV: coeficiente de variação; PC: peso corporal.

observaram diferenças significativas nas características de carcaça de suínos submetidos à restrição seguida de ganho compensatório.

Therkildsen et al. (2002), aplicando $40 \%$ de restrição alimentar no período dos 70 aos 140 dias de idade, observaram ao abate (100 kg PC) espessuras de toucinho semelhantes à dos animais sem restrição alimentar (Tabela 5).

Não foram observadas diferenças $(\mathrm{P}>0,05)$ nos pesos absolutos dos órgãos entre os níveis de restrição aplicados, o que está de acordo com resultados obtidos por Mersmann et al. (1987), Pond \& Mersmann (1990), Critser et al. (1995) e Lu et al. (1996). Em todos os níveis de restrição, verificou-se rápida resposta dos órgãos do sistema gastrointestinal com a retomada do consumo à vontade, o que pode ser atribuído ao fato de que o sistema digestório tem a capacidade de rápida adaptação às mudanças impostas no consumo de ração (Ratcliffe \& Fowler, 1980; Hornick et al., 2000; Carstens et al., 1991).

Os resultados das análises econômicas foram favoráveis à restrição aos 70 kg PC, em virtude do menor consumo de ração observado (Tabela 6).
No último período de restrição alimentar, a limitação do consumo resultou em economia maior de alimento, indicando vantagem de 3,53\% nos custos em relação à alimentação à vontade. No entanto, com os pequenos efeitos no ganho de peso e considerando a economia mínima no volume de ração consumida durante a fase de crescimento 1, em relação ao volume de todo experimento, no grupo com restrição aos $30 \mathrm{~kg}$ PC - os animais eram mais jovens e naturalmente consumiram menos ração-, o índice de custo e o índice de eficiência econômica pioraram nesse nível de restrição, o que pode ser atribuído ao manejo de restrição alimentar mais precoce, que afetou mais intensamente o índice de custo. Em comparação à restrição após os $70 \mathrm{~kg}$ PC, as restrições aos 30 e $50 \mathrm{~kg}$ PC resultaram em custos 12,54 e 4,70\% maiores.

\section{Conclusões}

A restrição alimentar de $20 \%$ do consumo à vontade durante 21 dias a partir dos 30, 50 ou 70 kg PC não afeta o consumo diário de ração, o ganho diário de peso e as 
Tabela 5 - Peso absoluto $(\mathrm{kg})$ das vísceras do sistema digestório de suínos submetidos a restrição alimentar

\begin{tabular}{lcccc}
\hline Órgão & \multicolumn{4}{c}{ Programa de restrição } \\
\cline { 2 - 4 } & $\begin{array}{c}\text { Sem restrição } \\
\text { alimentar }\end{array}$ & $\begin{array}{c}\text { Restrição aos } \\
30 \text { kg PC* }\end{array}$ & $\begin{array}{c}\text { Restrição aos } \\
50 \text { kg PC* }\end{array}$ & $\begin{array}{c}\text { Restrição aos } \\
\text { kg PC* }\end{array}$ \\
\hline Fígado & 1,630 & 1,538 & 1,570 & 1,580 \\
Estômago & 0,672 & 0,658 & 0,592 & 6,848 \\
Intestino delgado & 1,604 & 1,394 & 1,602 & 1,538 \\
Intestino grosso & 3,572 & 3,510 & 3,494 & 9,7072 \\
\hline
\end{tabular}

*20\% de restrição alimentar em relação ao grupo controle, durante 21 dias.

Letras diferentes indicam diferenças estatísticas pelo teste Tukey (5\%).

CV: coeficiente de variação; PC: peso corporal.

Tabela 6 - Avaliação econômica da aplicação de restrição alimentar em suínos nas fases de crescimento e terminação

\begin{tabular}{lcccc}
\hline Parâmetro & \multicolumn{2}{c}{ Programa de restrição } \\
\cline { 2 - 5 } & $\begin{array}{c}\text { Sem restrição } \\
\text { alimentar }\end{array}$ & $\begin{array}{c}\text { Restrição aos } \\
30 \mathrm{~kg} \mathrm{PC*}\end{array}$ & $\begin{array}{c}\text { Restrição aos } \\
50 \mathrm{~kg} \text { PC* }\end{array}$ & $\begin{array}{c}\text { Restrição aos } \\
\mathrm{kg} \text { PC* }\end{array}$ \\
\hline Custo da ração (R\$/kg de peso vivo ganho) & 0,88 & 0,96 & 0,89 & 104,70 \\
Índice de custo & 103,53 & 112,54 & 100,00 \\
Índice de eficiência econômica & 96,59 & 88,54 & 95,50 & 100,00 \\
\hline
\end{tabular}

*20\% de restrição alimentar em relação ao grupo controle, durante 21 dias. Letras diferentes indicam diferenças estatísticas pelo teste Tukey $(5 \%)$. PC: peso corporal.

características de carcaça, porém, as restrições nos pesos mais precoces comprometem mais a conversão alimentar, indicando que os ganhos subseqüentes ao manejo não foram suficientes para melhorar essa característica. A restrição a partir dos 70 kg de peso vivo melhorou a eficiência econômica de produção, portanto, é importante na avaliação do manejo.

\section{Literatura Citada}

ASSOCIAÇÃO BRASILEIRA DE CRIADORES DE SUÍNOS - ABCS. Método brasileiro de classificação de carcaças. 2.ed. Rio Grande do Sul: 1973. 17p.

ALVES, D.D. Crescimento compensatório em bovinos de corte. Revista Portuguesa de Ciências Agrárias, v.98, n.546, p.6167, 2003.

BARBOSA, H.P.; FIALHO, E.T.; FERREIRA, A.S. et al. Triguilho para suínos nas fases inicial de crescimento, crescimento e terminação. Revista da Sociedade Brasileira de Zootecnia, v.21, n.5, p.827-837, 1992.

BARBOSA, H.C.A.; VEIRA, A.A.; TEIXEIRA, Z.S. et al. Desempenho de suínos em terminação alimentados com diferentes níveis de restrição alimentar e de energia na dieta. Revista Brasileira de Ciências Veterinárias, v.9, n.3, p.147-153, 2002a.

BARBOSA, H.C.A.; VEIRA, A.A.; TEIXEIRA, Z.S. et al. Qualidade de carcaça de suínos submetidos à restrição alimentar na fase de terminação e abatidos em diferentes pesos. Revista Brasileira de Ciências Veterinárias, v.9, n.3, p.175-181, 2002b.

CARSTENS, G.E.; JOHNSON, D.E.; ELLENBERGER, M.A. et al. Physical and chemical components of the empty body during compensatory growth in beef steers. Journal of Animal Science, v.69, p.3251-3264, 1991.
CRITSER, D.J.; MILLER, O.S.; LEWIS, A.J. The effects of dietary protein concentration on compensatory growth in barrows and gilts. Journal of Animal Science, v.73, p.3376-3383, 1995.

DAZA, A.; RODRIGUEZ, I.; OVEJEDO, I. et al. Effect on pig performance of feed restriction during the growth period. Spanish Journal of Agricultural Research, v.1, n.4, p.3-8, 2003.

EMPRESA BRASILEIRA DE PESQUISA AGROPECUÁRIA EMBRAPA. Tabela de composição química e valores energéticos de alimentos para suínos e aves. 3.ed. Concórdia: Centro Nacional de Pesquisa de Suínos e Aves: 1991. 97p.

HORNICK, J.L.; Van EENAEME, C.; GÉRARD, O. et al. Mechanisms of reduced and compensatory growth. Domestic Animal Endocrinology, v.19, p.121-132, 2000.

IRGANG, R. rirgang@cca.ufsc.br. Predição do rendimento de carne na carcaça de suínos [mensagem pessoal]. Mensagem recebida por ambridi@hotmail.com em 2/7/2004.

KRISTENSEN, L.; THERKILDSEN, M.; AASLYNG, M.D. et al. Dietary-induced changes of muscle growth rates in pigs: effects on in vivo and postmortem muscle proteolysis and meat quality. Journal of Animal Science, v.80, p.28622871, 2002.

LU, C.D.; SCHOKNECHT, P.A.; ELLIS, K.J. et al. Differential compensatory organ growth in young pigs after short-term rehabilitation from protein deficiency. Nutritional Research, v.16, p.627-637, 1996.

MERSMANN, H.J.; MACNEIL, M.D.; SEIDEMAN, S.C. et al. Compensatory growth in finishing pigs after feed restriction. Journal of Animal Science, v.64, p.752-764, 1987.

NATIONAL RESERCH COUNCIL - NRC. Nutritional requirements of swine. 10.ed. Washington, DC.: National Research Council, 1998. 189p.

POND, W.G.; MERSMANN, H.J. Differential compensatory growth in swine following control of feed intake by high-alfalfa diet fed ad libitum or by limited feed. Journal of Animal Science, v.68, p.352-362, 1990.

RATCLIFFE, B.; FOWLWER, V.R.; The effect of low birth weight and early nutrition on subsequent development in pigs. Animal Production, v.30, p.470, 1980. 
ROPPA, L. [2005]. Produção mundial de carne suína. Disponível em:http://www.porkworld.com.br/porkworld/publicacoes.asp? pais=brasil\&codigo=42009. Acesso em: 18/4/2006.

UNIVERSIDADE FEDERAL DE VIÇOSA - UFV. SAEG - Sistema de Análises Estatísticas e Genéticas. Versão 7.1. Viçosa, MG: 1997. 150p. (Manual do usuário).
THERKILDSEN, M.; VESTRGAARD, M.; BUSK, H. et al. Compensatory growth response in pigs, muscle protein turnover and meat texture: effects of restriction/realimentation period. Animal Science, v.75, p.367-377, 2002.

WHITTEMORE, C. The science and practice of pig production. 2.ed. London: Longman Scientific \& Technical, 1993. 661p. 